\title{
HPLC analysis of blood-brain barrier penetration of 4-fluorodeprenyl
}

\author{
Zita Pöstényi ${ }^{\mathrm{a}, 1}$, Kornélia Tekes ${ }^{\mathrm{b}}$, Edit Tóth-Molnár ${ }^{\mathrm{c}}$, Huba Kalász ${ }^{\mathrm{a}, *}$ \\ a Department of Pharmacology and Pharmacotherapy, Semmelweis University, Nagyvărad têr 4, Budapest, Hungary \\ ${ }^{\mathrm{b}}$ Department of Pharmacodynamics, Semmelweis University, Nagyvărad tér 4, Budapest, Hungary \\ ${ }^{c}$ Department of Ophthalmology, University of Szeged, Szeged, Hungary
}

\section{A R T I C L E I N F O}

\section{Article history:}

Received 29 June 2014

Received in revised form

23 September 2014

Accepted 26 September 2014

Available online 30 October 2014

\section{Keywords:}

(-)-4-Fluorodeprenyl

HPLC

Rats

Blood-Brain barrier (BBB)

Lacrimal gland

\begin{abstract}
A B S T R A C T
Validated HPLC analysis was developed in order to monitor the level of 4-fluorodeprenyl in rats. Male Wistar rats were intraperitoneally treated with $30 \mathrm{mg} / \mathrm{kg}$ of (-)-4-fluorodeprenyl. The rats were sacrificed after 5, 15, 30 and 60 min of treatment, and various tissues were isolated, such as serum, brain, CSF, liver, testis and lacrimal gland. Perchloric acid was given to aliquots, which were then homogenized, centrifuged and the supernatants were taken. The 4-fluorodeprenyl content was determined using reversed-phase HPLC, based on the comparison of the calibration line of the spiked samples. The level of 4-fluorodeprenyl was between 0.5 and $24 \mu \mathrm{g} / \mathrm{g}$, showing maximum concentration in the brain and the liver after $5 \mathrm{~min}$ following its administration and in serum, CSF, testis, eyes and lacrimal gland after 15 min following its administration, while a relatively high concentration was found in the liver and the lacrimal gland.
\end{abstract}

(c) 2014 Elsevier B.V. All rights reserved.

\section{Introduction}

Racemic deprenyl (N, $\alpha$-methyl-N-2-propynyl-benzeneethanamine) was discovered and patented in 1962 by Ecsery et al. [1]. An early discovery showed that the human metabolism of deprenyl gives amphetamine and methamphetamine as major metabolites. As (-)-isomers of both amphetamine and methamphetamine have definitely less psychostimulant effect than the $(+)$-isomers, so (-)-deprenyl (selegiline) was synthesized and patented 3 years later [2]. The chemical structure of (-)-deprenyl is given in Fig. 1. The pharmacological spectrum of (-)-deprenyl was specified as early as in 1972 by Knoll and Magyar [3].

(-)-4-Fluorodeprenyl (IUPAC name: (-)-[1-(4fluorophenyl)propan-2-yl](methyl)(prop-2-yn-1-yl)amine) [4] is a halogenated derivative of (-)-deprenyl having essentially similar chemical properties and pharmacological effects. Simon et al. [5] studied the crystalline structure of enantiomeric hydrochlorides of deprenyl and that of its four derivatives (e.g. 4-fluorodeprenyl). In all cases the $\mathrm{CPhe}-\mathrm{C}-\mathrm{C}-\mathrm{N}$ torsion angle was anti-periplanar but in p-fluoro-amphetamine was gauche. The

\footnotetext{
* Corresponding author. Tel.: +36 302747486; fax: +36 12104417. E-mail addresses: postenyi.zita@gmail.com (Z. Pöstényi), drtekes@gmail.com (K. Tekes), tme@tmedit,hu (E. Tóth-Molnár), drkalasz@gmail.com (H. Kalász).

1 Permanent address: National Research Institute for Radiobiology and Radiohygiene, Budapest, Hungary.
}

level of 4-fluorodeprenyl in the brain was analyzed using gas chromatography-mass spectrometry by Lajtha et al. [6].

Nag et al. [7] used $\left[{ }^{18} \mathrm{~F}\right]$ derivatization of selegiline on the side-chain methyl of the isopropyl segment (Fig. 1). Brain incorporation and metabolism were investigated. Essentially slower metabolism was found than in the case of either selegiline (-)4-fluoro-deprenyl [7]. The uptake of $\left[{ }^{18} \mathrm{~F}\right]$ fluorodeprenyl was the highest in the corpus striatum (and thalamus), while lower incorporation was found in the cortical areas of the cynomolgus monkey brain. These findings correspond to the distribution of MAO-B activity detected and reported earlier using $\left[{ }^{11} \mathrm{C}\right]$ deprenyl [16]. Nag et al. [7] determined in vivo uptake of [ $\left.{ }^{18} \mathrm{~F}\right]$ fluoro-deprenyl by the brain, using positron emission tomography (PET) technique in two cynomolgus monkeys. The highest uptake was found in corpus striatum, while a lower uptake in the thalamus and the cortex and the lowest uptake were found in the cerebellum. They demonstrated uptake selectivity for MAO-B, that is the uptake was essentially inhibited by pre-treatment with selegiline (MAO-B enzyme specific inhibitor), but clorgyline (specific inhibitor of MAO-A enzyme) did not have any significant inhibitory effect. Plenevaux et al. $[8,9]$ described the synthesis and analysis of racemic 4$\left[{ }^{18} \mathrm{~F}\right]$ fluorodeprenyl and that of $(-)-4-\left[{ }^{18} \mathrm{~F}\right]$ fluorodeprenyl. They determined homogeneity of $4-\left[{ }^{18} \mathrm{~F}\right]$ fluorodeprenyl using both UV and radioactivity detectors. Plenevaux et al. [8,9] found very fast incorporation of $4-\left[{ }^{18} \mathrm{~F}\right]$ fluorodeprenyl in the brain of mice, and the brain offset of $(-)-4-\left[{ }^{18}\right.$ F fluorodeprenyl was faster than that of $(-)$ deprenyl from the brain. Brain versus blood level shows decreasing 
<smiles>C#CCN(C)[C@@H](C)Cc1ccccc1</smiles><smiles>C#CCN(C)[C@@H](C)Cc1ccc(F)cc1</smiles><smiles>C#CCN(C)[C@@H](C[18F])Cc1ccccc1</smiles>

Fig. 1. The chemical structure of (-)-deprenyl (top), (-)-4-fluorodeprenyl (centre) and $\left[{ }^{18} \mathrm{~F}\right.$ fluorodeprenyl (bottom).

ratios such as $2.03,1.72$ and 1.45 following 1,10 and $60 \mathrm{~min}$ following injection (into the lateral tail vein of female albion mice, strain BNL), respectively.

Magyar's experiments [10] found 4-fluorodeprenyl to be a definitely promising compound to substitute selegiline. Even 4-fluorodeprenyl showed less potent inhibitory effect on MAO$B$ enzyme in vitro than that of selegiline but its level was longer-lasting in vivo. Moreover, its desalkylated metabolites (4fluoroamphetamine and 4-fluoro-methamphetamine) were found more effective inhibitors of uptake than that of the parent compound. (-)-4-Fluorodeprenyl also shows more effective protection against neurodegenerative effects of the neurotoxin DSP-4 compared to that of (-)-deprenyl. Knoll et al. [11] showed that (-)-deprenyl and (-)-4-fluoro-deprenyl-treatment prevents agerelated pigment changes in the substantia nigra. Their results indicated that these two drug-treated groups do not differ significantly from each other in the number, total area and area of one pigment granule. Yasar et al. [12] investigated the behaviour of squirrel monkeys treated with (-)-4-fluorodeprenyl $(10 \mathrm{mg} / \mathrm{kg}$, i.m.). The methamphetamine-like discriminative stimulus required significantly higher doses than (-)-deprenyl (1.0-1.3 mg/kg, i.m.). The sexual activity of male Wistar rats (copulatory activity and ejaculation) was checked by using $0.25 \mathrm{mg} / \mathrm{kg}$, s.c. treatment with (-)-4-fluorodeprenyl. Three of (-)-4-fluorodeprenyl-treated sluggish rats kept their full sexual activity by the end of a 25 months' treatment. At the same time, the control Wistar rats lost their ejaculation ability earlier (Dallo and Knoll [13]). Lajtha et al. [6] found basic similarities between the metabolism of (-)-deprenyl and that of (-)-4-fluorodeprenyl following either central or peripheral administration. Knoll and Miklya [14] found that treatment with (-)-4-fluorodeprenyl enhanced the release of dopamine (from corpus striatum, substantia nigra and tuberculum olfactorium) and noradrenaline (from locus coeruleus), however, the (+)-enantiomer was more active than the (-)-form. Lajko et al. [15] investigated the effect of derivatization of deprenyl in 4-position with fluoride. This change did not only result in cell adhesion, but the chemotactic effect was also reversed. Selegiline ((-)-deprenyl) could result in significant (63.4\%) cytotoxic effect on MM6 monocyte cells, its $10^{-9} \mathrm{M}$ possesses antiproliferative character (88\%). Similar antiproliferative effects were observed in the case of the two enantiomers of $10^{-6} \mathrm{M} 4$-fluorodeprenyl ((-)-isomer $77.9 \%$ and (+)isomer $85.9 \%$ ).
Our aim was to determine pharmacokinetics of 4fluorodeprenyl using rats including serum, brain, CSF, liver, testis and lacrimal gland.

\section{Materials and methods}

\subsection{Chemicals and reagents}

Acetonitrile, sodium 1-decanesulfonate, citric acid monohydrate were purchased from Sigma-Aldrich (Schnelldorf, Germany), perchloric acid (PCA, 70\%) and sodium phosphate dibasic dihydrate were purchased from Merck (Darmstadt, Germany) in the best available purity. Phosphoric acid $85 \%$ was bought from Finomvegyszer Szövetkezet (Budapest, Hungary). Selegiline ((-)-deprenyl hydrochloride) and (-)-4-fluorodeprenyl hydrochloride were the kind gifts of Chinoin Pharmaceutical Company (Budapest, Hungary - its name is now Chinoin-Sanofi). The water used was Type 1 ultrapure water prepared in our laboratory (Direct-Q3, Merck Millipore, Darmstadt, Germany).

\subsection{Animals}

Male Wistar rats, weighing 200-205g were supplied by Toxicoop (Budapest, Hungary). All experiments conformed to 86/509/EEC regulation on the well-being of experimental animals, and the experimental protocol was approved by the local ethical committee (permission number: 1810/003/2004 ANTSZ, Budapest, Hungary).

Rats ( $n=4$, in each groups) were intraperitoneally (i.p.) treated with $30 \mathrm{mg} / \mathrm{kg}$ (-)-4-fluorodeprenyl hydrochloride freshly dissolved in double-distilled water. The rats were sacrificed after 5 , 15,30 and 60 min of treatment and the following tissues were isolated: serum, brain, CSF, liver, testis and lacrimal gland. The samples were stored at $-80^{\circ} \mathrm{C}$.

\subsection{Instruments and chromatographic conditions}

The chromatographic analysis was performed with a JASCO (Tokyo, Japan) system consisting of DG-2080-54 Degasser, PU-1580 HPLC Pump, AS-2057 Plus Autosampler (maintained at $4{ }^{\circ} \mathrm{C}$ ), UV$975 \mathrm{UV} /$ Vis Detector (operated at $265 \mathrm{~nm}$ ) and JMBS Hercule 2000 Chromatography Interface (Le Fontanil, France). Chromatograms were electronically stored and evaluated using Borwin 1.50 Chromatography Software (JMBS, Le Fontanil, France). The separation was done using a $(4.6 \mathrm{~mm} \times 250 \mathrm{~mm}, 5 \mu \mathrm{m})$ Zorbax Rx-C18 octadecyl silica column (Agilent Technologies, Santa Clara, CA, USA; supplied by Kromat Kft., Budapest, Hungary). The mobile phase consisted of $730 \mathrm{ml}$ of buffer $\left[10 \mathrm{~g} \mathrm{Na} \mathrm{HPO}_{4} \cdot 2 \mathrm{H}_{2} \mathrm{O}+10 \mathrm{~g}\right.$ citric acid + $10 \mathrm{mg} \mathrm{Na} \mathrm{N}_{2}$ EDTA + $25 \mathrm{mg}$ sodium 1-decanesulfonate dissolved in purified water, $\mathrm{pH}$ was adjusted to 3.7 with phosphoric acid] and $270 \mathrm{ml}$ acetonitrile (27\%). The mobile phase was filtered through a $0.45 \mu \mathrm{m}$ nylon membrane filter (Agilent Technologies) and then sonicated for 5 min using ultrasonic bath (Branson 2510). The flow rate of the mobile phase was $1 \mathrm{ml} / \mathrm{min}$, the temperature of the column was $35^{\circ} \mathrm{C}$ and the volume of injection was $40 \mu \mathrm{l}$.

\subsection{Preparation of stock and standard solutions}

Stock solution of (-)-4-fluorodeprenyl hydrochloride $(1000 \mu \mathrm{g} / \mathrm{ml})$ was prepared by dissolving the drug in doubledistilled water and further diluted with double-distilled water to obtain the different working standard solutions ranging from 0.2 to $50 \mu \mathrm{g} / \mathrm{ml}$. The stock solution was diluted to 5,10 and $50 \mu \mathrm{g} / \mathrm{ml}$ for the validation measurements. 


\subsection{Preparation of biological samples}

Dissected tissues from either untreated or treated animals were homogenized by an Ultra Turrax T25 Janke-Kunkel homogenizer (IKA Labortechnik, Staufen, Germany) at $20,000 \mathrm{rpm} / \mathrm{min}$ for $30 \mathrm{~s}$ at room temperature in $0.3 \mathrm{M}$ perchloric acid. The homogenates were centrifuged in an Eppendorf centrifuge (A. Hettich, Tuttlingen, Germany) with $14,000 \mathrm{rpm}$ for $20 \mathrm{~min}$ at $4^{\circ} \mathrm{C}$. The supernatant was collected for the further procedure.

\subsection{Method validation}

\subsubsection{Specificity}

To determine the specificity of the method, control serum samples, serum spiked with known amounts of the drug $(10 \mu \mathrm{g} / \mathrm{ml})$ and serum samples from Wistar rats after the i.p. dose of drug were analyzed.

\subsubsection{Peak purity}

The peak purity of (-)-4-fluorodeprenyl was determined by comparing the spectrum at three different regions of the spot i.e. peak start, peak apex and peak end (not shown here).

\subsubsection{Linearity}

The linearity was evaluated in the concentration range of $0.2-50 \mu \mathrm{g} / \mathrm{ml}$ at ten different levels of standard solutions $(0.2,0.5$, $0.7,1,2,5,7,10,20$ and $50 \mu \mathrm{g} / \mathrm{ml}$ ). Blank biological samples were spiked with standard solutions of 4-fluorodeprenyl at nine different levels $(0.5,0.7,1,2,5,7,10,20$ and $50 \mu \mathrm{g} / \mathrm{ml})$. Linearity was determined by the calculation of a regression linear line from the peak area versus concentrations of standard solutions and spiked samples using linear least squares methodology.

\subsubsection{Limit of detection and limit of quantification}

The limit of detection (LOD) is defined as the concentration of the analyte giving a signal-to noise-ratio of $3: 1$. The limit of quantitation (LOQ) of the assay is the smallest concentration that can be quantitated reliably with a specified level of accuracy and precision, giving a signal-to noise-ratio of $10: 1$.

\subsubsection{Precision}

The intra- and interday precision of the measurement were determined by percentage relative standard deviation (RSD). The intra- and inter-assay precisions were evaluated by analyzing the standard samples at 5,10 and $50 \mu \mathrm{g} / \mathrm{ml}$ concentration level of

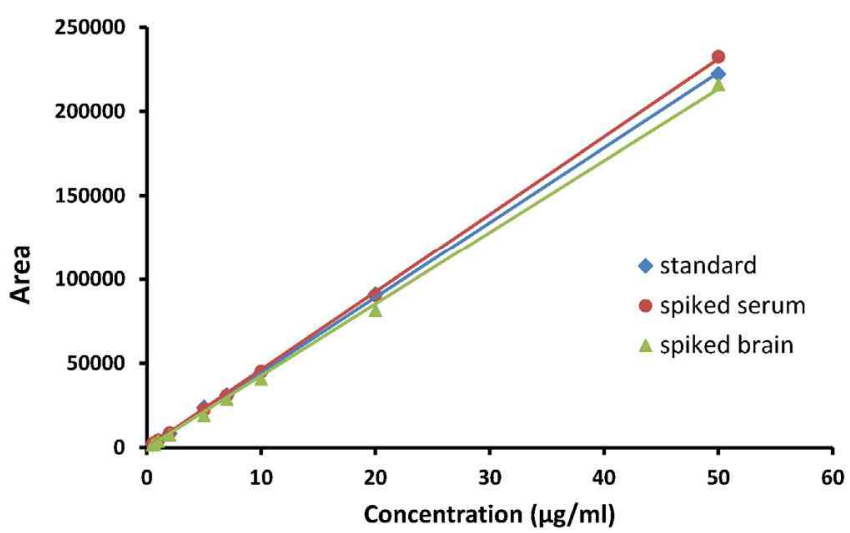

Fig. 2. 4-Fluorodeprenyl calibration lines: standard ( $\left.y=4462.7 x+0, R^{2}=0.9998\right)$, spiked serum $\left(y=4626.1 x+0, R^{2}=0.9998\right)$, spiked brain $\left(y=4267.9 x+0, R^{2}=0.9991\right)$.

(-)-4-fluorodeprenyl. For the intraday validation, six replicates of the standard samples were analyzed on the same day. For the interday validation, six replicates of the serum samples were analyzed on three different days. The results were expressed as $\mathrm{RSD} \%$ of the measurements.

\subsubsection{Robustness}

Robustness was determined by changing the mobile phase $\mathrm{pH}$ to 3.4 and 4.0 and the concentration of acetonitrile in the mobile phase to 22 and $32 \%$.

\section{Results}

The relation between peak area and concentration was linear $\left(R^{2}>0.999 ;\right.$ RSD 0.01) within the concentration range $(0.5-50 \mu \mathrm{g} / \mathrm{ml})$ in case of standard solution and also in the spiked serum and brain samples (Fig. $2 a-c$ ). Following the injection of blank samples there were no interfering peaks observed at the expected retention time of (-)-4-fluorodeprenyl which would disturb the determination. The precision studies indicated that the developed HPLC method was reproducible and the results are shown in Table 1 . The \% of RSD of robustness tested under different modified conditions is given in Table 2, indicating that the current method is robust. LOD and LOQ of (-)-4-fluorodeprenyl were 0.2 and $0.5 \mu \mathrm{g} / \mathrm{ml}$, respectively.

The distribution of 4-fluorodeprenyl in the rat was analyzed using reversed-phase HPLC-UV. The intact (-)-4-fluorodeprenyl

Table 1

Intraday and interday reproduction of (-)-4-fluorodeprenyl determination.

\begin{tabular}{|c|c|c|c|c|c|}
\hline Concentration added $(\mu \mathrm{g} / \mathrm{ml})$ & Area \pm SD & Concentration found $(\mu \mathrm{g} / \mathrm{ml} \pm \mathrm{SD})$ & $\operatorname{RSD}(\%)$ & Recovery $(\% \pm$ SD) & $n$ \\
\hline \multicolumn{6}{|l|}{ Intraday } \\
\hline 5 & $22,672 \pm 249$ & $4.89 \pm 0.05$ & 1.09 & $98.06 \pm 1.0$ & 6 \\
\hline 10 & $45,313 \pm 199$ & $9.99 \pm 0.04$ & 0.44 & $99.98 \pm 0.43$ & 6 \\
\hline 50 & $235,827 \pm 399$ & $50.30 \pm 0.08$ & 0.17 & $100.61 \pm 0.17$ & 6 \\
\hline \multicolumn{6}{|l|}{ Interday } \\
\hline 5 & $23,158 \pm 716$ & $5.00 \pm 0.15$ & 3.08 & $100.06 \pm 3.08$ & 18 \\
\hline 10 & $45,508 \pm 355$ & $10.00 \pm 0.07$ & 0.72 & $100.06 \pm 0.72$ & 18 \\
\hline 50 & $234,274 \pm 3196$ & $49.98 \pm 0.68$ & 1.36 & $99.95 \pm 1.36$ & 18 \\
\hline
\end{tabular}

Table 2

Robustness of (-)-4-fluorodeprenyl determination.

\begin{tabular}{|c|c|c|c|c|c|c|}
\hline \multirow[t]{2}{*}{ Robustness } & \multicolumn{3}{|c|}{ Acetonitrile \% of the mobile phase } & \multicolumn{3}{|c|}{$\mathrm{pH}$ of the mobile phase } \\
\hline & $22 \%$ & $27 \%$ & $32 \%$ & 3.4 & 3.7 & 4.0 \\
\hline Retention time ( $\mathrm{min}) \pm S D$ & $14.594 \pm 0.05$ & $12.791 \pm 0.02$ & $6.074 \pm 0.01$ & $12.322 \pm 0.02$ & $12.755 \pm 0.02$ & $14.516 \pm 0.03$ \\
\hline RSD\% & 0.39 & 0.21 & 0.23 & 0.16 & 0.16 & 0.25 \\
\hline
\end{tabular}



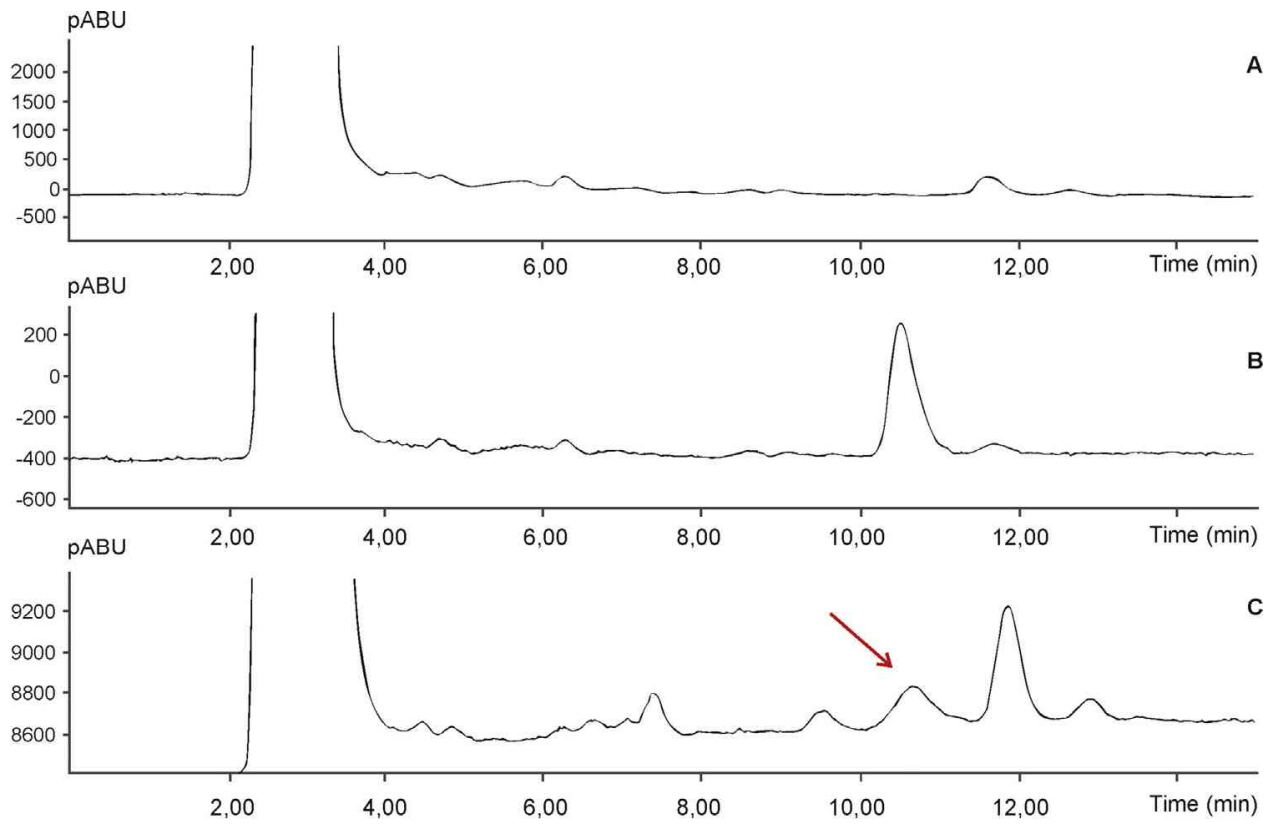

Fig. 3. (A-C) HPLC of rat serum samples (A: blank serum, B: spiked serum, C: serum sample from treated rat). The peak of (-)-4-fluorodeprenyl is marked with an arrow.

gave a distinct, well-resolved peak from the background from rat serum (Fig. 3A-C), brain (Fig. 4A-C), lacrimal gland (Fig. 5A-C), CSF, liver, testis and eyes (not shown here).

The tissue level of (-)-4-fluorodeprenyl was surprisingly high in the lacrimal gland following $15 \mathrm{~min}$ of i.p. injection and in the liver following 5 min of i.p. injection, and (-)-4-fluorodeprenyl showed continuous decline as shown in Table 3.

Comparing the level of $(-)$-4-fluorodeprenyl in the brain and CSF, it was significantly higher in the brain.

\section{Discussion}

Drug monitoring and biodistribution studies need a selective, simple and reproducible analysis. The developed method met these requirements, and it was validated.
The fast onset of 4-fluorodeprenyl can be explained by its definite lipophilicity. Our experiments used male Wistar rats that were subjected to intraperitoneal injections using (-)-4-fluorodeprenyl. The results mirrored similar results, such as fast onset of drug level. A surprisingly high content (related to the serum) was found in the lacrimal gland, liver and brain of the rats. Moderately slow offset took place in each part (organs and tissues) of the rats. The high level of (-)-4-fluorodeprenyl in the brain can be explained by its specific binding to the brain MAO-B enzyme [7].

The dose of (-)-deprenyl (selegiline) and its analogues depends on their indications. For classical human indication (parkinsonism), a dose of $10 \mathrm{mg} /$ day is recommended. This dose corresponds to a daily administration of $0.10-0.20 \mathrm{mg} / \mathrm{kg}$. As the indication of selegiline became wider, higher doses are also recommended in the case of deprenyl and its analogues used for the treatment of major

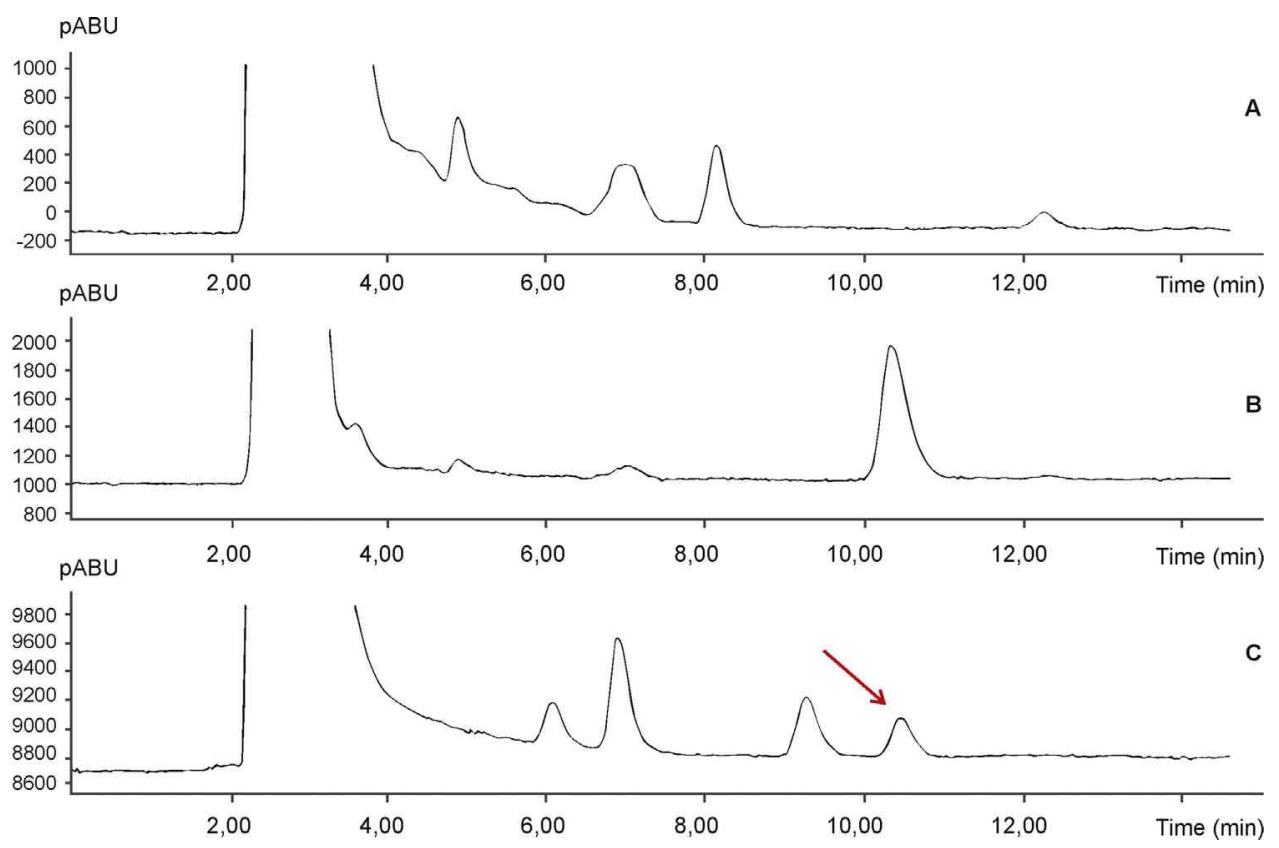

Fig. 4. (A-C) HPLC of rat brain samples (A: blank brain, B: spiked brain, C: brain sample from treated rat). The peak of (-)-4-fluorodeprenyl is marked with an arrow. 


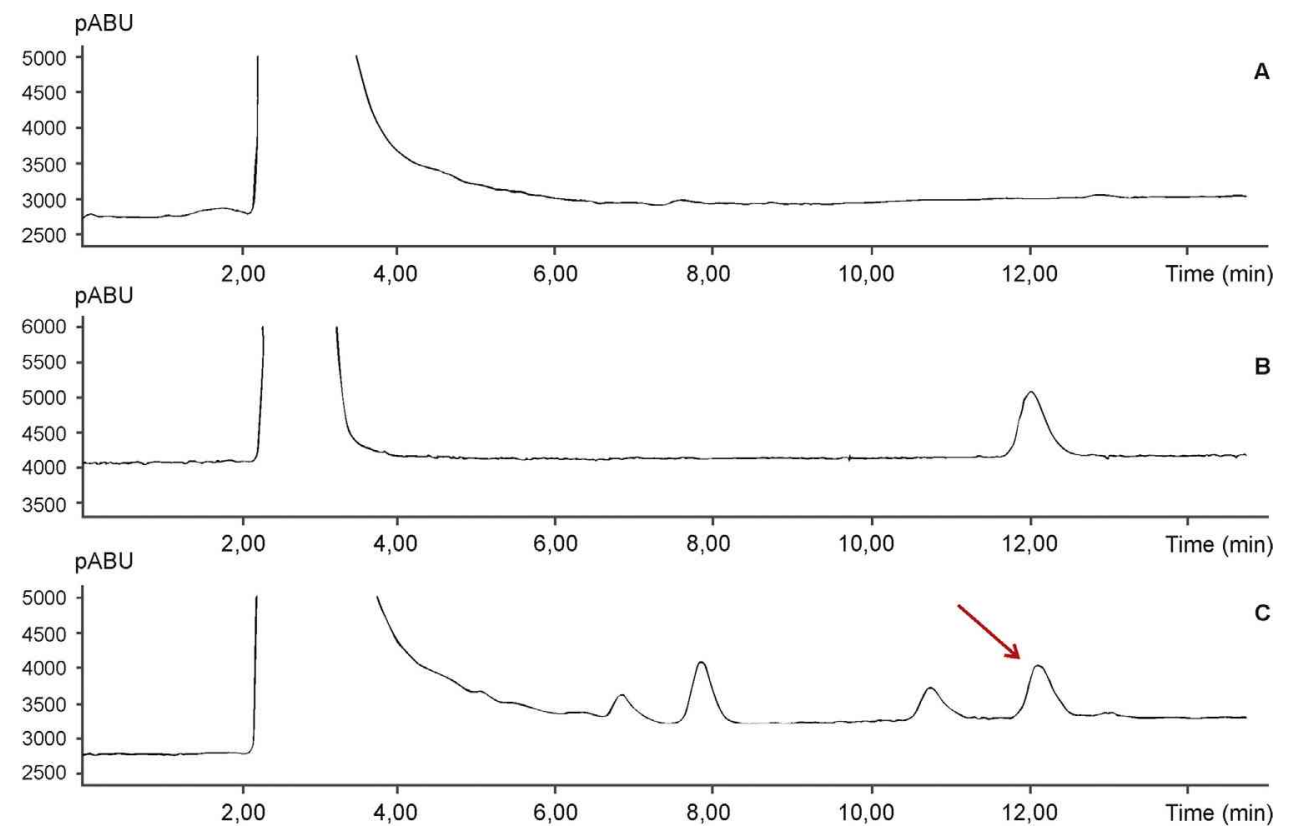

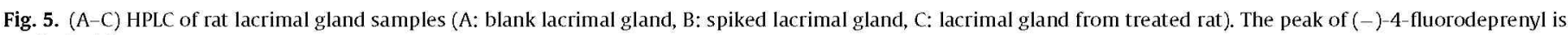
marked with an arrow.

Table 3

(-)-4-fluorodeprenyl content of various body fluids and tissues of rats following $30 \mathrm{mg} / \mathrm{kg}$ i.p. injection, $n=4$.

\begin{tabular}{|c|c|c|c|c|}
\hline \multirow[t]{2}{*}{ Samples } & \multicolumn{4}{|l|}{ Content $\pm S D$} \\
\hline & $5 \mathrm{~min}$ & 15 min & $30 \mathrm{~min}$ & $60 \mathrm{~min}$ \\
\hline $\operatorname{Serum}(\mu \mathrm{g} / \mathrm{ml})$ & $3.74 \pm 0.12$ & $5.53 \pm 1.08$ & $2.95 \pm 0.68$ & $1.72 \pm 0.34$ \\
\hline $\operatorname{Brain}(\mu \mathrm{g} / \mathrm{g})$ & $7.17 \pm 0.93$ & $4.66 \pm 1.5$ & $4.208 \pm 1.71$ & $1.89 \pm 0.59$ \\
\hline $\operatorname{CSF}(\mu \mathrm{g} / \mathrm{ml})$ & $1.11 \pm 0.21$ & $1.80 \pm 0.44$ & $1.22 \pm 0.08$ & $0.66 \pm 0.14$ \\
\hline Test is $(\mu \mathrm{g} / \mathrm{g})$ & $4.33 \pm 0.66$ & $5.80 \pm 1.63$ & $5.14 \pm 1.41$ & $3.44 \pm 1.18$ \\
\hline Liver $(\mu g / g)$ & $23.13 \pm 6.55$ & $18.03 \pm 3.26$ & $9.68 \pm 1.99$ & $7.06 \pm 1.27$ \\
\hline Eyes $(\mu g / g)$ & $1.70 \pm 0.24$ & $1.86 \pm 0.27$ & $1.65 \pm 0.44$ & $1.19 \pm 0.15$ \\
\hline Lacrimal glands ( $\mu \mathrm{g} / \mathrm{g}$ ) & $10.56 \pm 0.69$ & $15.82 \pm 5.78$ & $9.77 \pm 4.39$ & $8.17 \pm 2.79$ \\
\hline
\end{tabular}

depression using a transdermal patch (Emsam Patch). In veterinary medicine, a high dose of deprenyl is used for the treatment of the symptoms of Cushing's disease and cognitive dysfunction (Canine Cognitive Dysfunction). Low toxicity of (-)-deprenyl and its analogues may allow even higher doses of administration.

Quantitative analysis of (-)-deprenyl and (-)-4-fluorodeprenyl is possible using a wide choice of various analytical methods, such as mass spectrometry, radioactivity detectors, gas chromatography/mass spectrometry, HPLC/UV, HPLC/EC and HPLC/MS. HPLC is a generally used method, and HPLC with amperometric/electrochemical detection is quite sensitive, it can be recommended for quantitative determination of lower level of ( - )deprenyl and its analogues.

HPLC separation combined with a UV detector is the utmost simply manageable and inexpensive method for the quantitative analysis of (-)-deprenyl and its para-substituted analogues in the range of drug levels over $0.5 \mu \mathrm{g} / \mathrm{ml}$ in body fluids and tissues. Successful use HPLC/UV is one of the important novelties of this paper.

\section{Acknowledgements}

Thanks are due to Mr. János Horváth and Mr. Zoltán Demeter for their advice. This project was financially supported by the grant of the Hungarian Scientific Research Fund (OTKA T100155).

\section{References}

[1] Z.M. Ecsery, J. Knoll, É. Somfai, Process to develop a new drug containing derivative of phenyl isopropylamine, in Hungarian. Hungarian Patent, 151.090(1962)

[2] Z.M. Ecsery, J. Knoll, É. Somfai, Process to develop a new drug containing optically active derivative of phenyl isopropylamine, in Hungarian. Hungarian Patent, 154.655 (1965).

[3] J. Knoll, K. Magyar, Some puzzling pharmacological effects of monoamine oxidase inhibitors, Adv. Biochem. Psychopharmacol. 5 (1972) 393-408.

[4] Z. Ecsery, J., Knoll, E., Somfai, Z., Torok, E., Szinnyei, K. Mozsolics, N-2[(4-fluorophenyl)-1-methyl]-2-ethyl-N-methyl-N-propynyl amine and the method of use thereof. U.S. Patent 4960797 (1989).

[5] K. Simon, Z. Bocskei, Z. Torok, Study of selegiline and related compounds with X-ray diffraction, Acta Pharm. Hung. 62 (1992) 225-230.

[6] A. Lajtha, H. Sershen, T. Cooper, A. Hashim, J. Gaál, Metabolism of (-)-deprenyl and $\mathrm{pF}-(-)$-deprenyl in brain after central and peripheral administration, Neurochem. Res. 21 (1996) 1155-1160.

[7] S. Nag, A. Varrone, M. Toth, A. Thiele, G. Kettschau, T. Heinrich, L. Lehmann, C. Halldin, In vivo evaluation in cynomolgus monkey brain and metabolism of [(18)F]fluorodeprenyl: a new MAO-B pet radioligand, Synapse (Wiley, New York, NY) 66 (2012) 323-330.

[8] A. Plenevaux, J.S. Fowler, S.L. Dewey, A.P. Wolf, M. Guillaume, The synthesis of no-carrier-added DL-4-[ $\left.{ }^{18} \mathrm{~F}\right]$ fluorode prenyl via the nucleophilic aromat ic substitution reaction, Int. J. Radiat. Appl. Instrum. A: Appl. Radiat. Isotopes 42 (1991) 121-127.

[9] A. Plenevaux, S.L. Dewey, J.S. Fowler, M. Guillaume, A.P. Wolf, Synthesis of (R)$(-)$ - and $(S)-(+)-4$-fluorodeprenyl and $(R)-(-)-$ and $(S)-(+)-[N-11 C-$ methyl $]-4-$ fluorodeprenyl and positron emission tomography studies in baboon brain, J. Med. Chem. 33 (1990) 2015-2019.

[10] K.K. Magyar, Behaviour of (-)-deprenyl and its analogues, J. Neural Transm. Suppl. 41 (1994) 167-175.

[11] J. Knoll, M. Kummert, J. Sugár, (-)Deprenyl and (-)parafluorodeprenyl treatment prevents age-related pigment changes in the substantia nigra. A TV-image analysis of neuromelanin, Mech. Ageing Dev. 63 (1992) 157-163. 
[12] S. Yasar, J. Gaal, Z. Justinova, ]. Bergman, Discriminative st imulus and reinforcing effects of p-fluoro-L-deprenyl in monkeys, Psychopharmacology 182 (2005) 95-103.

[13] J. Dallo, J. Knoll, Effect of (-)-para-fluoro-deprenyl on survival and copulation in male rats, Acta Physiol. Hung. 79 (1992) 125-129.

[14] J. Knoll, I. Miklya, Multiple, small dose administration of (-)deprenyl enhances catecholaminergic activity and diminishes serotoninergic activity in the brain and these effects are unrelated to MAO-B inhibition, Arch. Intern. Pharmacodyn. Ther. 328 (1994) 1-15.
[15] E, Lajko, L. Polgar, O. Lang, J. Lengyel, L. Kohidai, K. Magyar, Basic cell physiological activities (celladhesion, chemotaxis and proliferation) induced by selegiline and its derivatives in Mono Mac 6 human monocytes, J. Neural Transm. 119 (5) (2012) 545-556.

[16] J.S. Fowler, R.R. MacGregor, A.P. Wolf, C.D. Arnett, S.L. Dewey, D. Schlyer, D. Christman, J. Logan, M. Smith, H. Sachs, et al., Mapping human brain monoamine oxidase A and B with 11C-labeled suicide inactivators and PET, Science 235 (1987) 481-485. 